\title{
IMPACTOS DA LEI 14.010/20 SOBRE A EXECUÇÃO DE ALIMENTOS PELO ENFOQUE DA TEORIA DOS JOGOS
}

\author{
IMPACTS OF LAW 14.010/20 ON THE ALIMONY ENFORCEMENT FROM THE \\ FOCUS OF GAME THEORY
}

\author{
Rafael Niebuhr Maia de Oliveira' ${ }^{1}$, Everaldo da Silva² \\ ${ }^{1}$ Advogado. Mestrando em Direito pela Universidade Federal de Santa Catarina, UFSC, Brusque, SC, Brasil, rafaelmaiaadv@gmail.com* \\ ${ }^{2}$ Sociólogo. Doutor em Sociologia Política, UFSC, Blumenau, SC, Brasil, prof.evesilva@gmail.com
}

\begin{abstract}
Resumo
No Brasil a economia passa por rápidas e profundas modificações desde a década de noventa. Os impactos dessas mudanças não caracterizam melhorias do ponto de vista de políticas públicas efetivas para a melhoria da saúde. Com a pandemia do Covid-19 isso também ficou latente, onde a economia nacional é atingida por crises que aprofundaram a ocorrência do fechamento de empresas e do crescente do desemprego. O impacto não é somente social e econômico, mas também jurídico. Nota-se que a partir da pandemia tivemos no Brasil a implantação da Lei no 14.010 , de $10 \mathrm{DE}$ junho de 2020, que dispõe sobre o Regime Jurídico Emergencial e Transitório das relações jurídicas de Direito Privado (RJET) no período da pandemia do coronavírus (Covid-19). Nosso objetivo nesse artigo foi compreender os impactos da Lei 14.010/20 sobre a execução de alimentos pelo enfoque da Análise Econômica do Direito (AED), mais especificamente pela Teoria dos Jogos. Para esse intento, a metodologia do estudo teve abordagem qualitativa, epistemologia interpretativista e lógica indutiva com apoio em pesquisa bibliográfica. Concluiu-se a partir da Análise Econômica do Direito (AED) que embora justificável tanto do ponto de vista social quanto de saúde pública, a proibição de recolhimento prisional do devedor de alimentos causará um déficit no caráter coercitivo da medida de prisão civil, o que deve levar aos credores a tomarem decisões estratégicas em relação a temporalidade do pedido de prisão.
\end{abstract}

Palavras-chave: Lei 14.010/20. Análise Econômica do Direito. Covid-19. Clausula Rebus Sic Stantibus. Prisão civil por alimentos.

\begin{abstract}
In Brazil, the economy has undergone rapid and profound changes since the 1990s. The impacts of these changes do not characterize improvements in terms of effective public policies for improving health. With the Covid-19 pandemic, this was also latent, where the national economy is hit by crises that deepened the occurrence of business closings and rising unemployment. The impact is not only social and economic, but also legal. It should be noted that since the pandemic, in Brazil we had the implementation of Law No. 14.010, of June 10, 2020, which provides for the Emergency and Transitional Legal Regime for Private Law legal relations (RJET) during the coronavirus pandemic period (Covid-19). Our objective in this article was to understand the impacts of Law 14.010 / 20 on food enforcement through the Law and Economics (AED) approach. For this purpose, the methodology used was the hypothetical deductive with support in bibliographic research. It was concluded from the Law and Economics (AED), more specifically by Game Theory that although justifiable both from a social and public health point of view, the ban on prisoners' imprisonment will cause a deficit in the coercive character of the civil prison measure, which it should lead creditors to make strategic decisions regarding the timing of the arrest order.
\end{abstract}

Keywords: Law 14.010/20. Law and Economics. Covid-19. Clause Rebus Sic Stantibus. Civil imprisonment for alimony.

CUNIS-MG. All rights reserved. 


\section{INTRODUÇÃO}

Atualmente, no Brasil, seguindo uma tendência internacional, está ocorrendo um significativo aumento do interesse político, econômico e acadêmico em relação as crises que afetam a sociedade com perspectivas de desenvolvimento.

O Brasil, nesse contexto, vem passando há um bom tempo por uma profunda reestruturação econômica, a qual contribui para a falência de algumas empresas, prejudicando sensivelmente as condições de trabalho e de emprego de milhares de trabalhadores. Logo, em 2020, com a pandemia do Covid-19, isso também ficou latente, onde a economia nacional é atingida por crises que aprofundaram a ocorrência de falências de empresas e crescente desemprego.

Dada às condições adversas que caracterizaram a pandemia, podemos afirmar que a situação de crise afeta, sensivelmente, os trabalhadores, sendo uma das formas a falência, ou seja, o fechamento da empresa. Alguns são credores, outros saem perdendo com um conjunto de direitos não assegurados, não apenas sem emprego, mas pior ainda, numa situação precária, aviltados de continuarem no mercado de trabalho.

Tenha-se presente que com a pandemia do Covid-19, que gerou perplexidade, exige uma análise em busca da compreensão do seu impacto não só do ponto de vista social e econômico, mas também jurídico.

Com efeito, a partir da pandemia tivemos no Brasil a implantação da Lei no 14.010, de $10 \mathrm{DE}$ junho de 2020, que dispõe sobre o Regime Jurídico Emergencial e Transitório das relações jurídicas de Direito Privado (RJET) no período da pandemia do coronavírus (Covid-19). Fato que teve impacto significativo, embora temporário, sobre a execução de alimentos.

Nesse sentido, objetiva-se compreender os impactos da Lei 14.010/20 sobre a execução de alimentos pelo enfoque da Análise Econômica do Direito (AED), mais especificamente pela aplicação da Teoria dos Jogos, por meio de uma observação pragmática de como as mudanças legislativas acima mencionadas impactam a tomada de decisão racional dos litigantes, como forma de fornecerIhes substrato teórico capaz de orientá-los na escolha da estratégia dominante em busca do bem da vida perseguido em ações judiciais desta natureza.

Para tanto, busca-se apoio na Análise Econômica do Direito (AED), teoria metodológica da análise do direito que surgiu com Richard Posner nos Estados Unidos, com foco em analisar as leis, tanto as que devem ser criadas, quanto as que existem e sua aplicação pelo método microeconômico. Logo, analisando por um ponto de vista behaviorista, a partir da teoria do indivíduo maximizador, ou seja, como os indivíduos respondem aos impulsos das leis e das normas com o escopo de obterem o melhor resultado possível.

O presente artigo é limitado, porquanto se objetiva apenas compreender os impactos da Lei 14.010/20 sobre a execução de alimentos pelo enfoque da Análise Econômica do Direito. Para esse intento, a metodologia do estudo teve abordagem qualitativa, epistemologia interpretativista e lógica indutiva com apoio em pesquisa bibliográfica.

O desenvolvimento do presente artigo é dividido em seções e subseções: 1. Introdução; 2. Análise Econômica do Direito; 3. Necessidade de Adaptação das Regras de Direito Privado em face das Alterações Sociais promovidas pela crise do Covid-19, sob enfoque da clausula Rebus Sic Stantibus; 4. Lei 14.010/20 e seus impactos sobre a execução de alimentos; 5 . Análise do art. 15 da Lei 14.010/20 sob o enfoque da Análise Econômica do Direito; Conclusão e Referências. 


\section{A TEORIA DOS JOGOS SOB A PERSPECTIVA DA ANÁLISE ECONÔMICA DO DIREITO}

Popularizada a partir das ideias de Richard Posner - embora se possa encontrar fundamentos em autores mais remotos, como Jeremy Bentham, por exemplo, a análise econômica do direito, ou AED como vem sendo chamada é assim conceituada por Gico Jr. (2010, p. 14):

o campo do conhecimento humano que tem por objetivo empregar os variados ferramentais teóricos e empíricos econômicos e das ciências afins para expandir a compreensão e o alcance do direito e aperfeiçoar o desenvolvimento, a aplicação e a avaliação de normas jurídicas, principalmente com relação às suas consequências.

Para além da busca "vã" (GICO JR, 2010, p. 12), pela essência ou vontade da norma ou do legislador, incapazes de avaliar as consequências práticas das decisões proferidas, a ciência econômica apresentaria ao direito alternativa metodológica capaz de permitir a tomada de decisões a partir da análise econômica de seus efeitos, "competindo, ao Direito, estipular o justo privado sem descuidar do custo social." (GONÇALVES, 2014, p. 264).

Nesse sentido, Marcellino Junior (2014, p. 86) destaca que Richard Posner, fundando sua teoria no pragmatismo filosófico, propôs a interpretação da norma sob o ponto de vista científico e objetivo, voltado aos efeitos e consequências das decisões judiciais. Assim, segundo Posner, estarse-ia limitando decisões tomadas com base em solipsismos, que seria substituído pela objetividade fornecida pela ciência econômica, cuja análise se fundaria na lógica da eficiência.

Nesse sentido é que a AED se mostra como "modelo teórico-prático útil à decisão judicial por meio da análise da realidade social, buscando melhorar os resultados gerais, promovendo, assim, o bem-estar social." (PEREIRA, 2015, p. 283 e 288).

Além da contribuição utilitarista, na medida em que permite "quantificar interesses, analisar procedimentos e indicar soluções com tendências probabilísticas que levem à dissipação dos conflitos e à satisfação das necessidades, bem como à elaboração Legislativa" (GONÇALVES, 2014, p. 269), a economia possibilita, a partir de uma perspectiva behaviorista, prever e estimular ou desestimular ações sociais desejáveis ou não. (MARCELINO JUNIOR, 2014, p. 128).

Isso porque, "os agentes econômicos ponderam custos e benefícios na hora de decidir, então, uma alteração em sua estrutura de incentivos poderá levá-los a adotar outra conduta, a realizar outra escolha." (GICO, JR., 2010, p. 22). Trata-se de lógica universal e aplicável ao direito, na medida em que normas, legislativas ou provenientes de decisões judiciais também tem o mesmo desiderato, qual seja, modular condutas para o standard social desejável.

Deste modo, na aplicação do método juseconômico, utiliza-se, primordialmente, a Análise Microeconômica, a partir do estudo da tomada de decisão pelo indivíduo, levando em consideração a dinâmica de interação entre agentes no processo judicial conforme se vê:

Uma ação judicial, para a parte litigante, seja ela autora ou ré, é uma decisão racional na qual são ponderados os custos e os benefícios esperados de se usar esse mecanismo social de resolução de conflito. Com ou sem a participação de advogados (como nos juizados especiais), ainda que intuitivamente, as partes tentam estimar a probabilidade de sucesso, bem como os custos associados à realização de um acordo ou de continuar litigando. Ambas as partes sabem que incorrem em uma margem de erro nessa estimativa. (GICO JR, 2014, p. 181) 
Deste modo, a aplicação da AED permite observar não apenas os efeitos que uma lei pode causar no conjunto social ao qual ela é direcionada, mas também a expectativa de direitos que a decisão judicial proferida em uma ação específica causará nas partes envolvidas naquela lide específica.

Além disso, por meio da AED, pode-se compreender também os efeitos que uma decisão de um caso pretérito podem causar nas ações futuras destas partes e de outras, que mesmo não envolvidas naquele litígio em específico, poderão ser encorajadas a agir de uma forma ou de outra, a partir da expectativa de direito que aquela decisão traz com relação a relações jurídicas futuras.

É exatamente o que defende Posner, citado por Pereira (2015, p. 281): The legal ruling will be precedent influencing the decision of future cases. The judge must therefore consider the probable impact of alternative rulings on the behavior of people engaged in activities that give rise to the kind of accident involved in the case before him ${ }^{1}$.

Dentre as técnicas que compõem a AED, pode-se mencionar a Teoria dos Jogos, caracterizada por Fabio Portela Lopes de Almeida (2003, p. 75) como "um dos ramos da matemática cujo desenvolvimento deu-se no século XX, em especial após a Primeira Guerra Mundial" e cujo objeto de estudo seria o conflito existente em situações conflitivas, em que partes diferentes almejam resultados diferentes. Neste contexto, considerando que cada envolvido utilizará de estratégias para maximizar seus ganhos, dentro de um contexto de regras pré-determinadas, esta teoria busca compreender qual seria a solução ótima em cada situação posta, considerando todas as variáveis envolvidas.

Assim, para uma correta avaliação da estratégia segundo a teoria dos jogos, é necessário que se especifique o modelo sobre o qual aquele jogo se desenvolverá, sob pena de se ignorar aspectos importantes dos jogos reais que se deseje estudar, causando uma assimetria de informações capaz de levar um jogador a tomar decisões erradas, justamente por não levar em conta no processo decisório todas as variáveis relevantes daquele modelo (FIANI, 2006, p. 8)

Ronaldo Fiani (2006, p.2) demonstrando a aplicação desta teoria para além da matemática, explica que "situações nas quais há interação estratégia podem ser caracterizadas como jogos". Há relatos de experiências bem sucedidas de aplicação da teoria em estratégias militares, ciências biológicas, física, economia, especialmente pela aplicação dada John Nash, que com a teoria do equilíbrio de Nash, baseado na Teoria dos Jogos, foi vencedor do prêmio Nobel de economia em 1994, chegando mais recentemente à ciência jurídica (ALMEIDA, 2003).

A utilização da teoria dos jogos no direito teve como marco precursor a teoria do Dilema do Prisioneiro ${ }^{2}$, muito utilizado nas ciências criminais para analisar técnicas como a delação premiada

\footnotetext{
1 Tradução livre do autor: A decisão legal gerará precedente, influenciando a decisão de casos futuros. O juiz deve, portanto, considerar o provável impacto de decisões alternativas no comportamento das pessoas envolvidas em atividades que dão origem ao tipo de conflito envolvido no caso que o antecede.

${ }^{2}$ De acordo com a estória de Tucker, formulada em carta enviada a Dresher, dois homens, suspeitos de terem violado conjuntamente a lei, são interrogados simultaneamente (e em salas diferentes) pela polícia. A polícia não tem evidências para que ambos sejam condenados pela autoria do crime, e planeja sentenciar ambos a um ano de prisão, se eles não aceitarem o acordo. De outro lado, oferece a cada um dos suspeitos um acordo: se um deles testemunhar contra o outro suspeito, ficará livre da prisão, enquanto o outro deverá cumprir a pena de três anos. Ainda há uma terceira opção: se os dois aceitarem o acordo e testemunharem contra o companheiro, serão sentenciados a dois anos de prisão. [...] Não há uma resposta correta ao dilema, mas a melhor alternativa, no caso, não é o equilíbrio de Nash[22], o que demonstra que o mesmo não é sempre a melhor alternativa (embora todo jogo tenha, no mínimo, um equilíbrio deste tipo). Se o jogo fosse disputado entre dois jogadores absolutamente racionais, a solução seria a cooperação de ambos, rejeitando o acordo com a polícia, sendo penalizados a 01 ano de prisão. Contudo, como não
} 
(ALMEIDA, 2003). No entanto, nos últimos anos sua aplicação vem sendo alargada, passando a ser analisada em diversas outras áreas do direito, como mecanismo capaz de oferecer resposta à crise de sobreuso do Poder Judiciário (SPENGLER; SPENGLER NETO, 2011); como forma de combater os oligopólios (ABRANTES, 2004); como método de análise da jornada de trabalho nas relações de emprego (MELLO, 2011), como apoio metodológico para obtenção da eficiência administrativa (DADALTO, 2018), como auxilio na tomada de decisão para recuperação judicial de empresas (SILVA, 2009), dentre outras aplicações.

Não se olvida que a base teórica que sustenta a Teoria dos Jogos, como espécie de aplicação da AED é alvo de muitas críticas, como se verifica em Heinen (2014, p. 2-3) que, com lastro em Polanyi, Lebaron e Bresser-Pereira se posiciona contra "o excesso de abstração (e de irrealismo) da economia neoclássica, buscando demonstrar que não são pressupostos neutros ou naturais como se propõe, mas escolhas políticas que poderiam, por serem escolhas, ser feitas de outra maneira." A autora destaca que a teoria de Posner se fundaria na ideia de equilibro geral de mercado, algo que está muito distante de se apresentar na realidade social, especialmente a brasileira.

Na sequência, a mesma autora assevera que Posner recentemente, após a crise econômica de 2008 (Subprime norte-americano) suaviza sua posição neoliberal, passando a se classificar como keyseanista, asseverando que este deveria rever sua teoria da AED, dessa vez com base nessa nova matriz econômica que passou a adotar.

As falhas do método AED são reconhecidas mesmo pelos autores brasileiros adeptos da análise juseconomica, como Gico Jr., que embora destaque que os valores a serem considerados pelos indivíduos não estão relacionados necessariamente com pecúnia, mas com os bens da vida mais caros a cada indivíduo, reconhece que o método será tão eficiente quanto a área do direito a ser analisada for possível de ser compreendida conforme a lógica de mercado.

É o que sustentam Gonçalves e Stelzer (2014, p. 282), quando defendem dentre outras estratégias no intuito de tornar o direito justo e capaz de proporcionar o desenvolvimento sustentável: "verificar a crise existente entre a ineficiência das regras de Direito e a busca da eficiência econômica, viabilizando soluções para que a aproximação das esferas normativas não se torne impossível em relação à realidade econômico-social". Nessa linha, os autores apresentam um marco-teórico a partir do qual se poderia pensar na aplicação da AED de uma forma que o alcance do bem comum fosse possível, o que fazem com base na teoria do Mínimo Ético Legal (MEL) e Princípio da Eficiência Econômico Social (PEES):

\begin{abstract}
Resta, pois, novo arranjo do Direito com a Economia, buscando eficiência, sim; porém, dentro de limites determinados pelo Estado, segundo se entende por Mínimo Ético Legal (MEL). Tal arranjo denomina-se Princípio da Eficiência Econômico Social (PEES). Destarte, justifica-se que, se a análise econômica de custos e benefícios pode não considerar critérios distributivos e, preconizando maiores lucros para um grupo, submeter outro a carências; por outro lado, a distribuição regressiva leva a maiores injustiças em termos materiais. Dessa forma, devem ser considerados critérios progressistas de distribuição da riqueza, segundo processo de tomada de decisão que não leve à estagnação ou inoperância da atividade econômica. (GONÇALVES, 2014, p. 272-273).
\end{abstract}

A par das divergência ideológicas, e considerando que a AED, e consequentemente a Teoria dos Jogos, não é capaz de solucionar todos os problemas jurídicos atuais, não se pode olvidar que este é um método viável e capaz de apresentar o arcabouço teórico capaz de auxiliar a

há garantia alguma de que a outra parte aja de forma cooperativa, este não é um equilíbrio de Nash (já que, nele, a melhor alternativa deve independer da vontade do outro jogador). (ALMEIDA, 2003, p. 181) 
compreensão, de maneira realista/pragmática, "da ação humana, a partir da alteração de sua estrutura de incentivos e, em última instância, como o direito pode elaborar tal estrutura para alcançar maior bem-estar social." (GICO JR., 2010, p. 29).

\section{CRISE DO COVID 19 SOB ENFOQUE DA CLAUSULA REBUS SIC STANTIBUS}

O direito privado brasileiro historicamente erguido sob os fundamentos do direito privado francês, estabelece os princípios liberais do direito das obrigações como pedra estrutural do direito contratual brasileiro, que parte da autonomia da vontade privada e do princípio pacta sunt servanda (OLIVEIRA, 2014).

O princípio do pacta sunt servanda, traduzido como o princípio da força obrigatória do contrato, apresenta estreita ligação com a autonomia da vontade privada e com a segurança jurídica, na medida em que garante que uma vez estabelecida obrigação de forma livre e autônoma por partes capazes, esta obrigação deve ser garantida pelo império do Estado (ROTTA; FERMENTÃO, 2008, p. 196).

A possibilidade do Estado agir sobre a vontade de um particular como forma de forçá-lo ao cumprimento de uma obrigação, embora a uma visão apressada possa parecer antagônico com a ideia de liberdade em si, justifica-se na medida em que o império do Estado só é exercido a partir da autorização tácita da parte que, ao firmar sua declaração de vontade em determinado contrato, permite ao Estado que haja sobre sua vontade, posteriormente, em caso de mora ou inadimplemento (OLIVEIRA, 2014).

Esses chamados princípios liberais do contrato, eis que estreitamente ligados com as ideias liberais segundo as quais o Estado não deveria intervir na esfera privada dos indivíduos tendem a afastar ideias e princípios que relativizem essa máxima, de modo que "admitir que um contrato pudesse ser revisto pelo Poder Judiciário, ainda que à vista de fatos supervenientes, extraordinários e alheios à vontade do devedor, implicava, na concepção liberal, numa indevida intromissão do Estado no conteúdo dos contratos." (MATTIUZO JUNIOR, 2002, p. 108)

Foi essa a regra que prevaleceu quase que soberana na redação do Código Civil de 1916, claramente inspirado no Código Napoleônico (LOUREIRO, 2008, p. 16), até vir a ser relativizada, embora não abandonada pelo Código Civil de 2002, surgido em meio a chamada fase de constitucionalização do direito privado brasileiro, inspirado claramente pelas ideias da Constituição Federal de 1988 com todo arcabouço de regras sociais que a caracteriza e a fez ser alcunhada de Constituição Cidadã (LÔBO, 2002).

Com o processo de constitucionalização do direito privado, Lotufo (2016) preconiza que se somaram a esses, três princípios, chamados de princípio sociais do contrato, que analisam a questão da autonomia privada de forma mais complexa, além da simples presunção de autonomia pela mera assinatura de um contrato, são eles: a boa-fé objetiva, o equilíbrio econômico do contrato e a função social do contrato.

Essa alteração de paradigma, é destacada por Mereniuk (2005, p. 120) como resposta da falência prática das ideias contratuais liberais "em consequência do flagelo econômico e financeiro que assola o país, cederam lugar a uma nova ordem de justiça distributiva que impõe, diante de uma relação de consumo, a assunção dos riscos do negócio pelo credor." 
Os resultados sócio-econômicos decorrentes das duas grandes guerras mundiais são apontados por Rotta e Fermentão (2008, p. 199) como fatores que contribuíram para essa guinada na interpretação do direito privado, na medida em que "refletiram, diretamente, nos contratos celebrados à época, havendo a necessidade de se reconhecer a ocorrência de fatos imprevisíveis que tornavam a execução dos mesmos, senão impossível, extremamente onerosa, para uma das partes."

Diante deste contexto, permitiu-se a relativização do pacta sunt servanda sempre que a obrigação tivesse sido contraída de forma a prejudicar preceitos sociais, sejam eles prejudiciais às proporias partes (boa-fé objetiva) ou à coletividade (função social do contrato). Assim, o Código Civil de 2020 se mostra como um marco na relativização dos princípios sociais, que passam a conviver de forma harmônica com os novos princípios sociais dos contratos (LÔBO, 2002).

Nesse sentido, mostrou-se necessária a busca do equilíbrio entre a liberdade contratual e econômica, e ainda, equilíbrio em relação ao poder do Estado em limitá-la, de modo que tal liberdade não representasse um meio de opressão e desrespeito aos direitos difusos, coletivos e individuais. Isso pois, a melhor solução não é a liberdade contratual plena e irrestrita, tampouco a intervenção estatal total, mas sim, um equilíbrio entre elas (OLIVEIRA, 2014, p. 211).

A partir desta nova realidade, Brito (2007, p. 165) afirma ser necessário estabelecer um equilíbrio da contratação no caso concreto, pelo que se faz imprescindível a presença do Estado para perquirir se o contrato é justo, equânime, em observância à equivalência material e ainda, se atenta aos limites do interesse geral em detrimento do interesse particular.

Ao lado da função social e da boa-fé objetiva, que em suma garantem que tanto na redação, quanto no cumprimento e até mesmo na fase pós-contratual, afastem-se estipulações contratuais que atentem contra a exigência de honestidade que devem ser cumpridas por todos envolvidos e a funcionalidade coletiva dos contratos, surge a clausula de resolução por onerosidade excessiva, baseada na teoria do rebus sic stantibus.

A origem desta teoria remonta a Idade Média, da seguinte frase: "Os contratos devem ser entendidos estando as coisas assim", ou seja, como se encontram no momento da contratação. Embora tenha sido posteriormente citada no direito francês no correr da primeira guerra mundial, acabou rechaçada pelos tribunais franceses, justamente pela tradição de respeito aos contratos que fundamenta o direito gaulês. (AZEVEDO, 2012, p. 54)

Leal (2003, p. 156), ao enxergar a clausula rebus sic stantibus como exceção ao pacta sunt servanda, esclarece que diante de a superveniência de fato capaz a desequilibrar economicamente o contrato enseja a prolação de decisão judicial "desobrigando a parte cuja prestação se tornou excessivamente onerosa, o que excepciona o princípio da força obrigatória - ou ainda a alteração do contrato, restabelecendo-se o equilíbrio entre as partes".

A sua previsão normativa pode ser encontrada junto a regra, que não continha correspondente no Código Civil de $1916^{3}$, e passa a ser expressamente prevista no Código de 2002, junto ao art. 478, assim disposto:

Art. 478. Nos contratos de execução continuada ou diferida, se a prestação de uma das partes se tornar excessivamente onerosa, com extrema vantagem para a outra, em virtude

\footnotetext{
${ }^{3}$ No Direito Brasileiro, conforme acima mencionado, não havia à época do Código Civil de 1916 norma expressa admitindo a aplicação da cláusula rebus (LEAL, 2003, p. 157).
} 
de acontecimentos extraordinários e imprevisíveis, poderá o devedor pedir a resolução do contrato.

Parágrafo único. Os efeitos da sentença que decretar a resolução do contrato retroagirão à data da citação.

Leal (2003) esclarece que embora diante destas circunstancias seja viável a resolução do contrato, com o consequente retorno ao status quo ante, tal consequência extrema é mitigada pelo próprio Código ante aos artigos 479 e 317, que permitem expressamente ao magistrado que evite a resolução, mantendo o contrato, ajustando, contudo, suas clausulas para que se reobtenha 0 equilíbrio econômico que se tinha na origem da obrigação.

Mattiuzo Junior (2002, p. 109) condiciona a aplicação deste mecanismo contratual a existência concomitante de quatro condições, a saber: a) alteração das condições econômicas quando comparado ao momento de sua celebração; b) imprevisibilidade destas modificações; c) que se trate de contrato de execução diferida ou de trato sucessivo; e d) que esta situação gere onerosidade excessiva a um dos contratantes proporcional ao lucro exagerado ao outro contratante.

Rotta e Fermentão (2008, p. 210) somam a estes requisitos a ausência de culpa do devedor, tido por estas, como um dos mais importantes requisitos, na medida em que "Se o acontecimento, imprevisto ou imprevisível, se deu por falha do devedor, este não pode arguir a teoria da imprevisão para pedir a intervenção judicial, no sentido de tentar revisionar a obrigação contraída".

Outrossim, a observância dos princípios sociais se mostra ainda mais relevante em casos extraordinários e imprevisíveis, como a crise de saúde gerada pelo COVID-19, que afeta diretamente todo o sistema de saúde, mas que também gera efeitos significativos sobre a ordem econômica e, por consequência, produz uma infinidade de efeitos sobre as relações jurídicas travadas nesse ambiente de instabilidade.

Ou seja, em tempos de comoção nacional pela pandemia, o princípio do rebus sic stantibus revela-se essencial para contornar a autonomia da vontade e o pacta sunt servanda, eis que a pandemia causada pelo Covid-19 e todas as consequências socioeconômicas a ele inerentes se subsumem exatamente a previsão do art. 478 do Código Civil, sendo pois, apta a aplicação deste dispositivo no casos concretos.

Neste cenário, a terrível pandemia da COVID-19 serve apenas para ilustrar a necessidade de se preservar e fortalecer estes importantes princípios na prática civil/comercial brasileira, não como forma de submeter os contratantes a uma indesejável insegurança, mas para que os contratos não sejam formulados de forma abusiva e ao arrepio de todo sistema social, econômico e ético impostos pela Constituição Brasileira de 1988.

\section{LEI 14.010/20 E SEUS IMPACTOS SOBRE A EXECUÇÃO DE ALIMENTOS}

Conforme se abordou no tópico anterior, o direito positivo brasileiro já possui instrumento legal capaz de regular as relações contratuais economicamente afetadas pelos efeitos da pandemia da Covid-19. Todavia, como todas as normas desta natureza, trata-se de norma aberta, cujo conteúdo indeterminado ao mesmo tempo que permite a sua adequação a casos não previstos expressamente pela lei, é capaz de causar insegurança jurídica, na medida em que admite interpretações divergentes. 
Assim, no afã de estabelecer de forma clara quais as situações deveriam, imperiosamente, serem relativizadas em razão da pandemia, em 10 de junho de 2020, foi publicada a Lei 14.010/20, fruto do PL 1.179, que dispõe sobre o Regime Jurídico Emergencial e Transitório das relações jurídicas de Direito Privado (RJET) no transcorrer do hodierno estado de calamidade em saúde pública.

Seguindo uma tendência mundial, como se observa de alterações legislativas emergenciais na Alemanha, Espanha, Estados Unidos, Inglaterra, dentre outros, o Brasil optou por prever regras específicas para regulamentar as relações jurídicas neste período de pandemia (SILVA, 2020).

Como ressalta Abelha (2020), momentos como este possibilitam a atuação legislativa de duas formas diversas, ou por meio de leis curtas e genéricas, permitindo ao magistrado que a adeque ao caso concreto, ou por normas específicas que indiquem com clareza e de forma impositiva a solução jurídica a ser aplicada naqueles casos arrolados pela lei.

Embora se possa encontrar na referida lei algumas normas que, embora especifiquem sua área de aplicação, ainda possuam conteúdo aberto, o fato é que na maioria dos artigos mantidos após os vetos presidenciais se tem normas de conteúdo bastante específicos, impondo sua aplicação naqueles casos descritos com pouca ou nenhuma margem de interpretação.

Logo em suas disposições gerais, a lei esclarece dois pontos essenciais: a) as normas ali descritas são de caráter transitório e em virtude do Covid-19, especificando o dia 20 de março, como termo inicial da situação extraordinária; e b) que nenhuma destas normas serão perenes, tratando-se de meras suspensões de aplicações de determinadas regras de direito que retornarão ao status quo ante após seu período de vigência.

A intenção do legislador era muito mais abrangente do que o texto sancionado revela, o que se verifica da quantidade de vetos presidenciais - 8 artigos dos 20 propostos restaram vetados - motivo de críticas, como as tecidas por Silva (2020), para quem "Não obstante os esforços empreendidos, a nova estrutura normativa revela retrocessos diante de outras leis mais avançadas e sobrepuja os interesses e os direitos das pessoas físicas e jurídicas que urgem de proteção no espectro privado."

Dentre os vetos mais destacados podem se citar a regra que impedia o cumprimento de medida liminar de despejo durante a pandemia e a regra que permitia ao síndico a adoção de medidas de restrição às áreas de uso comum com o objetivo de conter o contágio do vírus (ABELHA, 2020). Quanto ao último, enquanto Silva (2020) lamente a decisão ao afirmar que "Omitiu-se o governo federal sobre a sua obrigatória responsabilidade diante do nefasto quadro instalado", Abelha (2020, não paginado) o faz por outro motivo, porquanto entende que o sindico, mesmo sem a lei específica, continua com este poder, embora enxergue no veto um prejuízo quanto a segurança jurídica: "Infelizmente a atitude da Presidência da República causa imensa insegurança jurídica, passando à sociedade a mensagem equivocada e perigosa de que agora tudo pode."

Em apressada sínteses, as regras que sobreviveram ao veto presidencial são: suspensão dos prazos prescricionais e decadenciais durante esse período (art. 3ำ), inclusive o prazo para aquisição de bens imóveis por usucapião (art. 10); Possibilidade de realização de assembleias societárias (art. 5) e condominiais por meios eletrônicos (art. 12); Suspensão ao direito ao arrependimento de consumidores para compras feitas a distância de produtos perecíveis, de consumo imediato ou medicamentos (art. 80); Estabelecimento dos chamados carteis de crise, flexibilizando temporariamente as regras de direito anticoncorrencial (art. 14); Alargamento dos prazos do direito sucessório (art. 16). 
Além disso, estabeleceu-se uma das mais relevantes regras desta lei e que por opção metodológicas, é o centro de atenção deste artigo, quando no art. 15 "Estabeleceu-se que a prisão por dívida alimentícia deverá ser cumprida exclusivamente sob a modalidade domiciliar, sem prejuízo da exigibilidade das respectivas obrigações" (SILVA, 2020).

Deste modo, a prisão civil por alimentos expressamente autorizada na Constituição Federal (art. 50, LXVII) e no procedimento previsto nos artigos 528 e seguintes do CPC/15, passa a ser exercida, até o dia 30 de outubro de 2020, apenas mediante prisão domiciliar. Importante destacar que não houve o impedimento da prisão, mas tão somente a opção pelo cumprimento na forma de regime de prisão domiciliar expressamente prevista nos arts. 317 e seguintes do Código de Processo Penal em redação dada pela Lei 12.403 de $2011^{4}$.

\section{ANÁLISE DO ART. 15 DA LEI 14.010/20 SOB O ENFOQUE DA TEORIA DOS JOGOS}

Embora se costume a tratar dos alimentos no âmbito do direito de família, o fato é que se trata de obrigação, afeta, pois, as regras de direito das obrigações/contratual, razão pela qual se devem aplicar tanto os princípios liberais quanto sociais, dentre os quais se insere o princípio do rebus sic stantibus (MARINONI, 2018).

Assim, ao vetar de forma absoluta a possibilidade de prisão civil em estabelecimento prisional até o final de outubro de 2020, o legislador claramente se utiliza do princípio do rebus sic stantibus de modo a adequar a obrigação alimentar, e principalmente as consequências de seu inadimplemento, a uma nova realidade econômica imposta pela pandemia.

A subsunção da situação às regras de admissibilidade desta mitigadora do princípio pacta sunt servanda demonstra sua perfeita aplicação, na medida em que se trata de situação superveniente se comparada ao momento da fixação da obrigação alimentar; inesperada; aplicada a obrigação de trato sucessivo; capaz de impor a parte devedora, obrigação demasiadamente onerosa, especialmente a se considerar que a dívida alimentar é a única, no direito brasileiro, a admitir a sanção corporal pelo inadimplemento.

Aqui cabe a primeira crítica ao instituto, na medida em que pressupõe que todos os alimentantes seriam atingidos economicamente pela pandemia, o que lhes impediria de cumprir a obrigação alimentar no tempo e modo previstos em decisão judicial ou em acordo entre as partes. Ao optar por uma norma específica-impositiva, livra-se, por um lado, o devedor do ônus probatório de comprovar sua situação de fragilidade econômica em razão da pandemia, facilitando assim que este se beneficie da medida; enquanto, por outro lado, permite-se que pessoas não afetadas economicamente pela pandemia, também se valham desta benesse, mesmo não tendo qualquer alteração econômica em razão da pandemia.

Outro ponto que merece destaque é o fato de que não se observou a mesma compaixão com relação aos locatários de imóveis, cuja regra que impossibilitava o cumprimento de liminares de despejo foi vetada pelo presidente da república.

Ao se ponderar os interesses em jogo, poder-se-ia compreender a decisão na medida em que a restrição de liberdade, ainda mais em local altamente confinado, exporia o devedor de alimentos a risco muito maior do que aquele imposto ao devedor de alugueres que seria despejado. De outro lado, poder-se-ia enxergar a questão com foco no credor das obrigações, o que tiraria o sentido desta distinção, na medida em que os credores de alimentos se encontram em situação de

\footnotetext{
${ }^{4}$ Art. 317. A prisão domiciliar consiste no recolhimento do indiciado ou acusado em sua residência, só podendo dela ausentar-se com autorização judicial.
} 
inegável vulnerabilidade quando comparados aos locadores de imóveis, mesmo considerando que alguns destes utilizem dos alugueis como fonte de renda, porquanto, diferentemente dos alimentados, são, em regra, capazes de proverem sua própria subsistência de outro modo.

Outro fundamento que parece ter inspirado o citado artigo é a preservação da saúde dos devedores de alimentos. Nesse sentido, como sintetiza Alves (2020), a Lei é precedida por decisões proferidas no âmbito do STJ em sede de Habeas Corpus, bem como da Recomendação n. 62/2020 do CNJ, que recomendava "a colocação em prisão domiciliar das pessoas presas por dívida alimentícia, com vistas à redução dos riscos epidemiológicos".

Como já mencionado, a lei não veda a prisão em si, apenas condiciona o seu cumprimento ao regime domiciliar, previsto nos artigos 317 a 318 do Código de Processo Penal e que consiste, como diç̧ão do próprio artigo 317 do recolhimento do indivíduo em sua residência, só podendo dela se ausentar mediante autorização judicial.

Os casos de concessão dessa benesse, considerando o regime domiciliar muito mais favorável do que o regime ordinário de recolhimento ao cárcere são previstos no rol do artigo 318, do qual se extrai que a sua concessão está diretamente ligada ao princípio da dignidade humana, seja do próprio réu (incisos I e II), seja de incapazes que dele dependam (incisos III a VI).

Embora a prisão domiciliar seja vista por alguns como uma forma de coadunar a punição dos réus com o cumprimento dos deveres constitucionais do Estado em relação ao indivíduo, e até mesmo, advoguem pela eficiência dessa medida, como no caso de Cadore e Steffens (2020), para outros, como Pontes (2018, p. 198), que ao tratar especificamente da prisão domiciliar em caso de paternidade/maternidade, assim se manifesta: "Isso se tornaria um perfeito escudo da impunidade, dado que a mulher poderia se valer dessa situação para continuar praticando delitos protegida pela legislação. E, para que continue solta, bastaria que tivesse outro filho."

Araken de Assis, ao tratar especificamente quanto a prisão civil por alimentos, esclarece que o caráter coercitivo da medida só se mostrará eficaz caso o devedor acredite que possa realmente ser preso em caso de inadimplemento: "É preciso deixar bem claro ao alimentante relapso, a quem se assegurou, previamente, oportunidade para defesa, que, inadimplidos os alimentos, a pena concretizar-se-á da pior maneira, através de seu confinamento em presídio comum" (GRISARD FILHO, 2015).

Isso porque, como se sabe, a medida da prisão por alimentos se trata de medida coercitiva específica, com o claro objetivo de forçar o devedor a realizar o pagamento da obrigação alimentar, que por sua natureza e essencialidade do bem jurídico protegido justificam medida tão extrema (TALAMINI, 2018). De acordo com Câmara (2016, p. 87), este grupo de tutelas é nominada de execução indireta e consiste no emprego de medidas voltadas a coagir o próprio obrigado a praticar os atos necessários à satisfação da obrigação na tutela específica.

Neste sentido, Talamini (2018, p. 144) destaca que "para ser eficaz, a medida de coerção terá de impor ao réu um sacrifício, sob certo aspecto, maior do que o que ele sofreria com o cumprimento do dever que lhe cabe". Ou seja, no caso dos alimentos, o sacrifício em seu cumprimento é a diminuição do patrimônio do devedor, ante a transferência de renda ao alimentado. Assim, para que seja eficaz, a medida coercitiva de causar temor maior do que este, sob pena de correr sério risco de inocuidade ao depender meramente da consciência moral do devedor.

Em outras palavras, ao se prever a possibilidade de prisão civil do devedor, ou de qualquer outra medida coercitiva, não se está a punir o devedor por sua inadimplência, mas sim compelindo- 
a a encontrar meios de saldar a obrigação alimentar perante aquele que dele depende financeiramente.

E desta forma, quanto maior for o temor infligido ao devedor, maior será a efetividade da medida. Razão pela qual se pode afirmar que ao vedar a prisão comum do devedor de alimentos, o art. 15 reduz de forma significativa o poder de coerção que a medida será capaz de produzir sobre o mesmo, dificultando o cumprimento da medida, e em última análise, o recebimento do credito de alimento pelo credor.

Na perspectiva da análise econômica do direito, a Teoria dos Jogos vem sendo utilizada em diversas áreas além da economia, dentre elas o direito, no qual dela se utiliza como instrumento de análise ampliado, capaz de formular as "expectativas de comportamento estratégico, partindo-se do pressuposto de ações racionais". Assim, considerando a teoria do sujeito otimizador, tenta-se prever as ações processuais a serem tomadas por cada parte envolvida em um processo judicial em busca do melhor resultado para si, que no caso do processo é a decisão mais favorável (ROSA, 2017, p. 67).

A previsão das atitudes dos sujeitos processuais é melhor apreendida por meio da Teoria do Equilíbrio de Nash, que parte da compreensão de que "o resultado processual não depende exclusivamente da performance de um jogador, mas decorre da interação humana, das táticas e estratégias dominantes/dominadas utilizadas no limite temporal do processo" (ROSA, 2017, p. 68), de maneira que a atitude de um jogador influencia, decisivamente no resultado do jogo, como ocorre no clássico Dilema do Prisioneiro.

Partindo desse marco teórico metodológico, é de se antecipar que a atitude dominante de um devedor contumaz de alimentos, desde que tenha conhecimento da Lei 14.010/20, considerando a popularização da informação jurídica propiciada pelo avanço da internet, seja a de ficar menos compelido ao cumprimento da obrigação.

A depender da região do país em que residir o Devedor, e dependendo de sua situação laboral, em tempos de isolamento social, de possível suspensão do contrato de trabalho (por força da Medida Provisória 936), ou até mesmo de decreto de lockdown, em cidades que optarem por esta alternativa, o decreto de prisão domiciliar pode não ter efeito algum, na medida em que o devedor já estaria impedido de sair de seu domicílio de qualquer forma.

E muito embora o cumprimento do período de prisão domiciliar não ilida a obrigação alimentar, conforme reforça a parte final do próprio art. 15 da lei em comento, o fato é que a jurisprudência tem se mostrado contrária a renovação do pedido de prisão, ao menos com relação aos valores que fundamentaram a prisão anterior.

Ou seja, em sendo preso em regime domiciliar, e não pagando a quantia devida, o Devedor, em tese, não mais poderá ser preso, desta vez em regime fechado como é a regra ordinária, por este débito.

Em conhecendo a tendência do devedor de, diante do art. 15 da Lei 14.010/20, permanecerse inerte a ordem de cumprimento da obrigação alimentar, ou seja, conhecendo a estratégia dominante do devedor de alimentos, o credor, do outro lado da relação processual deve ponderar qual deverá ser a sua estratégia dominante: pedir a prisão mesmo assim, contando com o bom senso do devedor, ou aguardar para pleitear tal medida em novembro, quando não mais vigorará a restrição do art. 15, possibilitando que então se requeira o pagamento dos três meses anteriores, agosto a outubro, além daqueles que se vencerem ao longo da demanda, sob pena de prisão, dessa vez, em regime fechado. 
Não se pode olvidar que se está a tratar de débito de natureza alimentar, de modo que nem sempre a parte terá condições de aguardar meses para o recebimento de quantia que prejudicam sua subsistência. Por outro lado, como se sabe, o mero pedido e a correspondente ordem de pagamento, quando desprovidas de tutela processual realmente capaz de compelir o devedor ao cumprimento, não se mostram suficientes à quitação desta obrigação.

Outra ressalva importante a se fazer é a que outra condicionante da coercitivade da ameaça de prisão domiciliar é o efetivo controle da sanção, que quando não acompanhada de dispositivos eletrônicos, como no caso das tornozeleiras eletrônicas, torna ainda mais inócua a medida, na medida em que depende do controle caso-a-caso e de forma presencial pela força policial, que já demasiadamente atarefada ${ }^{5}$, não tem meios para controlar de forma efetiva o cumprimento da sanção.

De todo modo, o mais importante é ter em mente que, como sói ocorrer em qualquer analise processual pela Teoria dos Jogos (ROSA, 2017, p. 67), cada caso envolverá sujeitos, objetos e circunstâncias diversas, de modo que a segregação, ainda que domiciliar possa ser suficientemente grave para um devedor que, por exemplo, desempenhe trabalho eminentemente externo, ou que por qualquer outra circunstância se sinta verdadeiramente compelido ao cumprimento da obrigação perseguida.

Deste modo, a decisão a ser tomada pelo credor não pode observar apenas a sua necessidade premente, mas também todas estas circunstâncias capazes de atuar na vontade e na estratégia do litigante oposto a si, proporcionando a tomada de decisão capaz de fornecer o melhor resultado possível ao credor.

\section{CONCLUSÃO}

Neste artigo, tentou-se problematizar a constituição e a emergência do debate sobre os impactos da pandemia do Covid-19 no Brasil, especificamente do ponto de vista jurídico. O objetivo do artigo foi de compreender os impactos da Lei 14.010/20 sobre a execução de alimentos pelo enfoque da Análise Econômica do Direito.

Discutiu-se também a necessidade de Adaptação das Regras de Direito Privado em face das Alterações Sociais promovidas pela crise do Covid-19, sob enfoque da clausula Rebus Sic Stantibus. Em seguida, apresentou-se a Lei 14.010/20 e seus impactos sobre a execução de alimentos. E, por fim, analisou-se o art. 15 da Lei 14.010/20 sob o enfoque da Análise Econômica do Direito.

Nota-se que a hermenêutica - por qualquer de suas vertentes -, concentrados na descoberta da sua essência ou da sua vontade ou ainda de quem as criou, possui métodos que não tem demonstrado a eficiência necessária a resolução de uma gama de problemas afetos ao sistema de justiça. Logo, peremptoriamente no caso do Covid-19 e seu impacto do ponto de vista social, econômico e jurídico precisava de uma análise qualitativa das decisões e interpretações jurídicas.

Nesse sentido, concluiu-se que a Teoria dos Jogos no contexto da Análise Econômica do Direito (AED) é uma metodologia útil e aplicável para as análises das decisões judiciais e do impacto disso na coletividade e nos indivíduos, porque contribuiu para o entendimento de uma práxis cidadã e solidária.

\footnotetext{
${ }^{5}$ Para chegar à média de um policial para cada 450 habitantes como recomenda a Organização das Nações Unidas (ONU), o Brasil precisaria ganhar 20 mil policiais em seu efetivo da Polícia Militar. (EXAME, 2017)
} 
Por todos os argumentos apresentados durante o artigo conclui-se que o objetivo principal foi atingido, que era de compreender os impactos da Lei 14.010/20 sobre a execução de alimentos pelo enfoque da Análise Econômica do Direito, no sentido que embora se possa justificar a flexibilização da prisão civil nesse momento, seja em razão da aplicação da cláusula rebus sic stantibus, em face das mudanças socioeconômicas imprevisíveis, ou ainda por razões de saúde pública, é inegável que esta medida atingirá também pessoas não afetadas de forma significativa pela pandemia e que, dela se valerão para não cumprirem suas obrigações alimentares, eis que não mais ameaçados pela possibilidade de prisão civil em estabelecimento prisional.

Diante deste cenário, e com espeque na Teoria dos Jogos, é necessário ao credor que, antes de tomar sua decisão processual, analise o cenário por inteiro, compreendo os estímulos capazes de influenciar a tomada de decisão de seu adversário processual, o que se faz necessário para que com sua ação possa atingir o melhor resultado possível, qual seja, o recebimento, no menor tempo possível, de seu crédito alimentar. Assim, a estratégia dominante, no caso concreto, pode representar até mesmo aguardar até novembro de 2020, quando não mais incidirá a regra do art. 15 da Lei 14.010/20, permitindo-se, então, a prisão civil do executado em estabelecimento prisional, caso não efetue o pagamento das parcelas de agosto em diante.

Certamente, apesar de ser um tema novo e que merece análises mais profundas, julga-se que este artigo oferece algumas contribuições relevantes para análise sobre a Lei 14.010/20 e seus impactos na execução de alimentos.

Ante ao curto espaço de tempo entre a entrada em vigor da lei e a finalização desta pesquisa, não se pode constatar se e em que grau os efeitos aqui apontados foram realmente sentidos na prática forense. Desta forma, sugere-se que em futuras pesquisas se proceda com estudo empírico acerca dos resultados práticos que a lei em análise trouxe para a realidade dos cumprimentos de sentença de obrigações de natureza alimentar, como forma de comprovar ou não as hipóteses aqui formuladas e, via de consequência, a assertividade da teoria dos jogos e da análise econômica do direito no direito brasileiro.

\section{REFERÊNCIAS}

ABELHA, André. A lei 14.010/20 e o direito imobiliário: imperfeita e necessária. Migalhas. Disponível em: https://www.migalhas.com.br/coluna/migalhas-edilicias/328822/a-lei-14010-20-eo-direito-imobiliario-imperfeita-e-necessaria. Acesso em: 22 jun. 2020.

ABRANTES, Maria Luísa. A Teoria dos Jogos e os Oligopólios. Angola: Multitema, 2004.

ALMEIDA, Fábio Portela Lopes de. A teoria dos jogos: uma fundamentação teórica dos métodos de resolução de disputa. Estudos em arbitragem, mediação e negociação, p. 175, 2003.

ALVES, Jones Figueirêdo. Uma jurisprudência de família (re)construída na pandemia. Consultor Jurídico. Disponível em: https://www.conjur.com.br/2020-jun-14/processo-familiarjurisprudencia-familia-reconstruida-pandemia. Acesso em: 22 jun. 2020.

AZEVEDO, Álvaro Villaça. Inaplicabilidade da teoria da imprevisão e onerosidade excessiva na extinção dos contratos. Em Estudos de Homenagem ao Prof. Doutor Jorge Miranda, vol. vi. Coimbra: Coimbra Editora/Faculdade de Direito da Universidade de Lisboa, 427-442. 2012. 
CADORE, Ana Luiza; STEFFENS, Alessandra Franke. A possibilidade de conversão da prisão em regime fechado em prisão domiciliar durante a pandemia do Coronavirus. Anuário Pesquisa e Extensão Unoesc São Miguel do Oeste, v. 5, p. e24429-e24429, 2020.

CÂMARA, Alexandre Freitas. O princípio da patrimonialidade da execução e os meios executivos atípicos: lendo o art. 139, IV, do CPC. Revista Diálogos, v. 2, n. 1, p. 84-94, 2016. Disponível em: http://ojs.fapce.com.br/index.php/dialjurifap/article/view/36. Acesso em: 02 jun. 2020.

DADALTO, Lucas Dutra. Controle judicial da eficiência administrativa: aplicação da teoria dos jogos como ferramenta auxiliar. Revista de Direito Administrativo e Gestão Pública, v. 4, n. 1, p. 18-36, 2018.

EXAME. Os estados com o maior déficit de policiais por habitante: Média do país precisa melhorar para chegar a um policial para 450 habitantes como recomenda a ONU; Maranhão é o pior estado. Publicado em: 03 set. 2017. Disponível em: https://exame.com/brasil/brasil-temdeficit-de-20-mil-policiais-em-seu-efetivo/ . Acesso em: 07 out. 2020.

FIANI, Ronaldo. Teoria dos jogos: para cursos de administração e economia. 2 ed. rev. e atual. Rio de Janeiro: Elsevier, 2006.

GICO JR, Ivo Teixeira. A tragédia do Judiciário. In: RDA - Revista de Direito Administrativo, Rio de Janeiro, v. 267, p. 163-198, set./dez. 2014

GICO JR. Ivo Teixeira. Metodologia e Epistemologia da Análise Econômica do Direito. In: Economic Analysis of Law Review, V. 1, no 1, p. 7-33, Jan-Jun, 2010

GONÇALVES, Everton das Neves; STELZER, Joana. Princípio da Eficiência Econômico-Social no Direito Brasileiro: a tomada de decisão normativo-judicial. In: Sequência. v. 35, n. 68, p. 261-290, jun. 2014.

GRISARD FILHO, Waldyr. O futuro da prisão civil do devedor de alimentos: caminhos e alternativas. In: PEREIRA, Rodrigo da Cunha. Família e Dignidade Humana: Anais do V Congresso Brasileiro de Direito de Família. Belo Horizonte: IBDFAM: IOB Thomson. 2015.

HEINEN, Luana Renostro. A Análise Econômica do Direito de Richard Posner e os pressupostos irrealistas da economia neoclássica. In: Direito e economia I [Recurso eletrônico on-line] organização CONPEDI/UFSC; coordenadores: Gina Vidal Marcílio Pompeu, Felipe Chiarello de Souza Pinto, Everton das Neves Gonçalves. - Florianópolis: CONPEDI, 2014

LEAL, Luciana de Oliveira. A onerosidade excessiva no ordenamento jurídico brasileiro. Revista da EMERJ, v. 6, n. 21, p. 155-165, 2003.

LÔBO, Paulo Luiz Netto. Constitucionalização do direito civil. Revista de informação legislativa, v. 141, 1999. Disponível em: https://www2.senado.leg.br/bdsf/item/id/453. Acesso em: 25 Abril 2020. 
LÔBO, Paulo Luiz Netto. Princípios sociais dos contratos no CDC e no novo Código Civil. Revista Jurídica da UNIRONDON, p. 11-12, 2002.

LOTUFO, Renan. Código Civil comentado, v.3. São Paulo: Saraiva Educação, 2016.

LOUREIRO, Lourenço Trigo de. Instituições de direito civil brasileiro. Revista CEJ, v. 8, n. 25, p. 107$108,2008$.

MARCELLINO JUNIOR, Júlio Cesar. O direito de acesso à justiça e a análise econômica da litigância: A maximização do acesso na busca pela efetividade. Tese (Doutorado em Direito) Programa de Pós-Graduação em Direito, Universidade Federal de Santa Catarina. Florianópolis, 2014.

MARINONI, Luiz Guilherme. Técnica processual e tutela dos direitos. 5 ed. rev., ampl. e atual. de acordo com o CPC/2015. São Paulo: Thomson Reuters Brasil, 2018.

MATTIUZO JUNIOR, Alcides. A teoria da imprevisão e a revisão dos contratos no Novo Código Civil. Revista Jurídica da UNIRONDON. n. 3. 2002/1. Cuiabá, 2002.

MELLO, Simone Barbosa de Martins. A jornada de trabalho na perspectiva da teoria dos jogos. Dissertação (Mestrado em Direito) - Pontifícia Universidade Católica de São Paulo, São Paulo, 2011.

MERENIUK, Ruy Orlando. Teoria da imprevisão- A doutrina keynesiana frente ao Código Civil. Revista CEJ, v. 10, n. 35, p. 62, 2008.

OLIVEIRA, Rafael Niebuhr Maia de. A limitação da liberdade de contratar como fonte de efetivação de direitos. In: NONES, Nelson; SILVEIRA, Adriana Bina da; HARTZE, Suzete Habitzreuter (Coord.). Desafios para o Direito Empresarial. Blumenau: Legere Editora, 2014.

PEREIRA, Leonardo Fadul. Análise econômica do direito e pragmatismo jurídico: algumas noções sobre a teoria de Richard A. Posner. In: 0 pensamento jurídico contemporâneo. Coordenação Jean Carlos Dias. - Rio de Janeiro: Forense; São Paulo: MÉTODO, 2015.

PONTES, Darwin de Souza. Drogas, crime organizado, mães e filhos e a conversão de prisão preventiva em domiciliar. Revista da AJURIS, v. 45, n. 144, p. 183-206, 2018.

ROSA, Alexandre Morais da. Guia do processo penal conforme a teoria dos jogos. 4. Ed. Florianópolis: Empório do Direito, 2017.

ROTTA, Mariza; FERMENTÃO, Cleide Aparecida Gomes Rodrigues. < b > O Pacta Sunt ServandaCláusula Rebus Sic Stantibus e o Equilíbrio das Relações Contratuais na Atualidade. Revista Jurídica Cesumar-Mestrado, v. 8, n. 1, p. 193-218, 2008.

SILVA, Fernando César Nimer Moreira da. Incentivos à decisão de recuperação da empresa em crise: análise à luz da teoria dos jogos. 2009. Tese de Doutorado. Universidade de São Paulo. 
SILVA, Joseane Suzart Lopes da. Lei 14.010/20 deveria melhor atender às necessidades emergenciais dos brasileiros. Consultor Jurídico. Disponível em: https://www.conjur.com.br/2020jun-16/direito-civil-atual-lei-1401020-deveria-melhor-atender-necessidades-brasileiros. Acesso em 22. Jun. 2020.

SPENGLER, Fabiana Marion; NETO, Theobaldo Spengler. A possibilidade do tratamento de conflitos no âmbito do Judiciário por meio da Teoria dos Jogos. Desenvolvimento em Questão, v. 7, n. 13, p. 63-86, 2009.

TALAMINI, Eduardo. Poder geral de adoção de medidas coercitivas e sub-rogatórias nas diferentes espécies de execução. Revista de Processo. vol. 284, 2018. 